Jonathan Senchyne. 2020. The Intimacy of Paper in Early and Nineteenth-Century American Literature. Studies in Print Culture and the History of the Book. Amherst, MA: University of Massachusetts Press, pp. 176, 10 illustr., \$90.00.

Reviewed by Alexander Starre, Freie Universität Berlin

E-Mail: alexander.starre@fu-berlin.de

https://doi.org/10.1515/ang-2021-0020

In a passage of her sweeping one-volume history of the United States These Truths, Harvard historian Jill Lepore chronicles Benjamin Franklin's proverbial rise "from rags to riches". To this shopworn phrase, Lepore adds her own twist when she contrasts Benjamin's career with the life story of his sister Jane Franklin: "paper is made of rags, and Franklin, the first American printer to print paper currency, turned rags to riches. Jane [...] lived the far more common life of an eighteenth-century American and especially of a woman, born poor: rags to rags" (2018: 60). Pulling the rags-to-riches metaphor down to earth, Lepore highlights the unpleasant, mundane, and ugly flipside to the stately career of one of early America's representative men. Discussing the academic rhetoric of book historians in the larger domain of literary studies, Leah Price describes such interpretive debunking as part of a larger trend in which "the hermeneutics of suspicion has given way to a poetics of deflation" (2012: 22). As we can see in Lepore's writing, addressed to a broad, non-specialist readership as it is, this type of materialist thinking about the infrastructure of public culture has spread far beyond the confines of bibliographically oriented scholarship. It would be tempting to enlist Jonathan Senchyne's The Intimacy of Paper in Early and Nineteenth-Century American Literature (2019) in this deflationary school of criticism, given that the book is centered on rag paper and opens with the startling sentence "Do you see this 
paper?” (1). Instead of ushering the reader into a detached space of scholarly expertise, this opening line deflects from analytical language and throws the materiality of the scholarly monograph into sharp relief. Still, "deflation" is not at all what Senchyne is after; rather, he aims to think through the communicative function and the affective resonance of paper as the material substrate that fostered ideas of statehood, community, and identity in the long formative period from about 1690 to 1867.

As only experts of paper and printing history will recognize, these years bookend a distinct media historical era: the rag paper period. In 1690, the first paper mill of the colonies began operating in Pennsylvania, and in 1867 "a wood-based pulp replaced a rag-based pulp as the primary ingredient in the majority of American papermaking" (Senchyne 12). Thankfully for the non-initiated, Senchyne includes a "Brief History of American Rag Papermaking" in his introduction. The bulk of The Intimacy of Paper rests on a unique archive ranging from early American periodicals, broadsides, and print advertisements on the one hand, to literary texts by Anne Bradstreet, Lydia Sigourney, Herman Melville, and William Wells Brown on the other. The comparative angle of the study does not so much differentiate between the affordances of fictional and nonfictional artifacts, but instead puts all discursive artifacts in conversation with their material, papery substratum. While this may sound like an overly detailed and granular focus, Senchyne does not shy away from addressing the large superstructure of American public culture erected on this medial foundation. In the book's first chapter, he deploys the concepts of 'paper publics' and 'paper nationalism' to engage with the canonical scholarship of Jürgen Habermas, Benedict Anderson, and Michael Warner, all of whom have elevated print to a critical component within the modern public sphere and the emergence of the nation-state. Skillfully synthesizing public-sphere scholarship and its recent gender- and class-based critiques, Senchyne's paper public draws a multitude of overlooked individuals and institutions into the open: "The orientation toward rags and paper over print [...] reveals a wider range of actors around the material text: female domestic laborers working with cloth, indigent ragpickers, papermakers" (40). Presenting select examples from colonial and early Republican newspapers, Senchyne shows how the precariousness of the North American print public unsettled readers, authors, and printers alike, as the scarce supply of reusable textile fabric threatened the very possibility of unifying a national print public in the time of revolution and independence. Patriotic calls to help in the preservation and collection of linen fabric circulated on the very paper that owed its existence to these rags. As such, Senchyne argues against and beyond Anderson, national consciousness "is not produced merely by the arrival of the newspaper in serial time but from the specter of the newspaper's absence" and "arises out of awareness of the strangers 
whose rags are mixed into paper in contact with your own, not the notion of strangers who read the same text elsewhere" (50).

In chapter 2, Senchyne further develops the notion of intimacy as connected to paper. His extended account of the work of Puritan poet Anne Bradstreet unfolds a larger argument on women's literacy and authorship, but it does so with a close reading of Bradstreet's “The Author to Her Book” (1650)-especially its selfreflexive evocation of the "ill-formed offspring of my feeble brain" that is "made in raggs" en route to publication (Bradstreet, qtd. in Senchyne 2020: 73). Senchyne recounts how recent feminist scholarship has broadened our understanding of the relationship between Bradstreet, the author, and her metaphorical evocation of children and motherhood. He builds on this work by insisting that the metaphor need not only be contextualized in an ideational sense, but also within the material entanglements of the book itself. In his perceptive close-reading, he follows the "made in raggs" metaphor not only to the abstract domains of motherhood and authorship, but even more suggestively back to the body of the book: "it is through that metaphor that the reader begins to see that the cloth of child-rearing literally is the book" (85; original emphasis). The very rag paper on which Bradstreet's poetry was originally printed actively collaborates in this metaphorical-material interplay, as Senchyne shows with an exhibit from the Library of Congress copy of The Tenth Muse (1650), which carries visible pieces of cloth rag permanently incorporated within its sheets of paper. In Lydia Sigourney's “cloth poems”, Senchyne sees a mid-nineteenth-century correlative to Bradstreet's subversion of authorial voice, noting how Sigourney found apt motifs in pieces of silk, cotton, and linen that allowed her to transgress the gender-coded Victorian separation of private and public and to challenge "the partitions that circumscribed her" (94).

A chapter on Melville and Thoreau addresses the ways in which the intimate connectivities embodied in paper evolve as the U.S. papermaking trade becomes industrialized. Where Thoreau confronted this moment with speculations on how the raw materiality of cloth and rags can sensually affect modern humans, Melville-in Senchyne's reading-pursued a very different aesthetic project, primed on "the erotics of rag paper" in a dawning age of mass print (119). Melville's fawning letters to his friend Nathaniel Hawthorne carry curious ideas about the strange connectivity that paper epistles generate. Especially in Melville's short story "The Paradise of Bachelors and the Tartarus of Maids" (1855), the erotic tension of Melville's letters morphs into a literary allegory of queer sociality. The Fourdrinier machine that churns out endless rolls of paper not only acts like a machine in the proverbial garden of hand papermaking as craft; it also becomes an emblem of the problematically globalized modern marketplace and of the unprecedented connections it establishes between separate domains. Lothar Müller already ana- 
lyzed Melville's short story from a material text-perspective in his White Magic: The Paper Age (2014), a book with a similar focus that is absent from Senchyne's otherwise impressive array of critical literature.

In its final move, The Intimacy of Paper can be said to reverse its argumentative thrust. Throughout Senchyne's discussion of paper publics and the literary life of print media, rag paper in its multiple incarnations always figures as an integrative agent that materially draws together spheres that are discursively separated (the home and the workplace, the filthy streets and the pristine study, the gentlemanly salon and the feminized factory floor). In chapter 4, however, this unifying function fades as Senchyne turns to the strange overlay between the contrastive pair of black ink and white paper on the one hand and the antebellum period's racial binary of whiteness and blackness on the other. Paper connected social spheres, to be sure, but it also served as a material metaphor meant to cleave apart evolving race categories. As Senchyne convincingly shows, the great value placed in the manufacture of pure white paper had more than a trivial correspondence to the racial hierarchies between white, black, and brown: "Like a white page grounding black print, racial whiteness seemed to be the natural invisible background against which differently marked bodies could be read" (128). Confronting didactic poems and illustrations from the time, the chapter shows how the production and conservation of paper whiteness entered an uneasy alliance with the cultural work of consecrating racial hierarchies, especially with regard to white femininity. An illuminating close reading of William Wells Brown's Clotel (1853) ends the chapter, showing how a mixed-race, light-skinned heroine posed a problem for the book's original frontispiece, whose illustrators used ink shading to reinforce the black-and-white binary on paper.

The Intimacy of Paper moves in on its subject(s) from the margins, as book historical scholarship often does-both in the figurative and in the literal sense. Several central developing lines of American literary and cultural history are paired with episodes well off the beaten historiographic path, such as the rumored use of mummy wrappings from Egypt for paper manufacture in the United States or the paper shortage in the Confederate South during the Civil War that lead to curious editions of newspapers printed on wallpaper. Senchyne's book further stands out through its illuminating cross-pollination of recent theoretical concerns with early American studies. The conceptual thinking of Craig Dworkin, Lisa Gitelman, and Ben Kafka enriches the study's media historical narrative of the rag paper period. This transhistorical traffic of ideas has been a marker of material text studies in general, though often in the reverse direction, with scholars of contemporary literature and digital media such as Amaranth Borsuk, Johanna Drucker, Katherine Hayles and others building on the historical work of print scholars and extending it into the present. 
The biggest contemporary influence on the study, though, is the work of Hans Ulrich Gumbrecht, whose theorization of 'presence' has already sparked numerous projects in literary and cultural studies, especially in Europe. Senchyne deftly shows how a focus on 'presence effects' created by paper can enrich our understanding of the historical world of literature, but also of the contentious political fields of citizenship, gender, and race in the American context. Where Gumbrecht less-than-subtly advertises his presence-concept as an intellectual antidote to politically engaged cultural criticism, Senchyne appears to tacitly refute Gumbrecht on several levels without making this explicit as he traces the multiple ways in which the presence of paper is (and always has been) political. Perhaps the book could have followed through with this theoretical critique in a more thorough fashion; then again, a comprehensive theory of presence is not Senchyne's stated goal here. Rather, he hopes to contribute to a new form of "critical bibliography" that dissolves "barriers between theoretically informed cultural studies and deep attention to the materiality of texts" (7). In this, The Intimacy of Paper succeeds brilliantly not only as a scholarly contribution for specialists of early and nineteenth-century American culture, but also as an innovative methodological intervention in American Studies more broadly.

\section{Works Cited}

Lepore, Jill. 2018. These Truths: A History of the United States. New York: Norton. Müller, Lothar. 2014. White Magic: The Age of Paper. Malden, MA: Polity Press.

Price, Leah. 2012. How to Do Things with Books in Victorian Britain. Princeton, NJ: Princeton University Press. 